\title{
Nasal Cavity and Paranasal Sinuses Cancer cNX TNM Finding v8
}

National Cancer Institute

\section{Source}

National Cancer Institute. Nasal Cavity and Paranasal Sinuses Cancer cNX TNM Finding v8. NCI Thesaurus. Code C133049.

Nasal cavity and paranasal sinuses cancer in which the regional lymph nodes cannot be assessed. (from AJCC 8th Ed.) 